\title{
Bilateral testicular self-castration due to cannabis abuse: a case report
}

\author{
Mustapha Ahsaini" ${ }^{*}$, Fadl Tazi', Abdelhak Khalouk', Karim Lahlaidi', Abderahim Bouazzaoui², \\ Roos E Stuurman-Wieringa ${ }^{3}$, Mohammed Jamal Elfassi ${ }^{1}$ and My Hassan Farih ${ }^{1}$
}

\begin{abstract}
Introduction: The self-mutilating patient is an unusual psychiatric presentation in the emergency room. Nonetheless, serious underlying psychiatric pathology and drug abuse are important background risk factors. A careful stepwise approach in the emergency room is essential, although the prognosis, follow-up, and eventual rehabilitation can be problematic.

We present a unique and original case of bilateral self-castration caused by cannabis abuse.

Case Presentation: We report a case of a 40-year-old Berber man, who was presented to our emergency room with externalization of both testes using his long fingernails, associated with hemodynamic shock. After stabilization of his state, our patient was admitted to the operating room where hemostasis was achieved.

Conclusion: The clinical characteristics of self-mutilation are manifold and there is a lack of agreement about its etiology. The complex behavior associated with drug abuse may be one cause of self-mutilation. Dysfunction of the inhibitory brain circuitry caused by substance abuse could explain why this cannabis-addicted patient lost control and self-mutilated. To the best of our knowledge, this is the first case report which presents an association between self-castration and cannabis abuse.
\end{abstract}

\section{Introduction}

Self-inflicted testicular injuries are an uncommon phenomenon but do represent the most frequent form of genital mutilation (61\%) [1]. Most self-inflicted testicular injuries have been reported in transsexual patients who desire emasculation or by psychotic patients with either functional or organic brain diseases like schizophrenia or a severe personality disorder $[2,3]$.

Amphetamine use [4] and cocaine use [5] have been associated with severe self-injurious behavior. To the best of our knowledge self-castration engendered by cannabis abuse has never been reported.

We report an uncommon case of a man with self-castration resulting from cannabis addiction.

\section{Case Presentation}

We describe the case of a 40-year-old Berber man, originally from Morocco, who presented to our emergency

\footnotetext{
*Correspondence: drahsaini@gmail.com

'Department of Urology, Hospital University Center Hassan II, 30000 Fez, Morocco

Full list of author information is available at the end of the article
}

room with self-inflicted testicular injuries. His medical history was marked by tuberculosis of the lung. His psychiatric history dated from 32 years of age, when he was treated due to alcohol and cannabis abuse. Many medical treatments and psychotherapy techniques were proposed for detoxification but they failed because of his poor compliance with therapy. At the time of admission, he had not consumed alcohol for several months, but he reported using cannabis, particularly a few hours before the act. No childhood trauma, personality or even borderline personality disorders (assessed as a lifetime diagnosis) were diagnosed. He reported no psychiatric or medical diseases among close relatives. He presented to our emergency room eight hours later with unilateral scrotal laceration (Figure 1) and externalization of both testis (Figure 2) using his long fingersnails (Figure 3). This was associated with hemodynamic shock. Our patient underwent vascular filling and blood transfusion to achieve stabilization of his state. Upon examination of our patient's perineum, one wound was visible on the top of his right hemiscrotum measuring $4 \mathrm{~cm}$ with ecchymosis extended from his scrotum to the inguinal
Ciomed Central

() 2011 Ahsaini et al; licensee BioMed Central Ltd. This is an Open Access article distributed under the terms of the Creative Commons Attribution License (http://creativecommons.org/licenses/by/2.0), which permits unrestricted use, distribution, and reproduction in any medium, provided the original work is properly cited. 


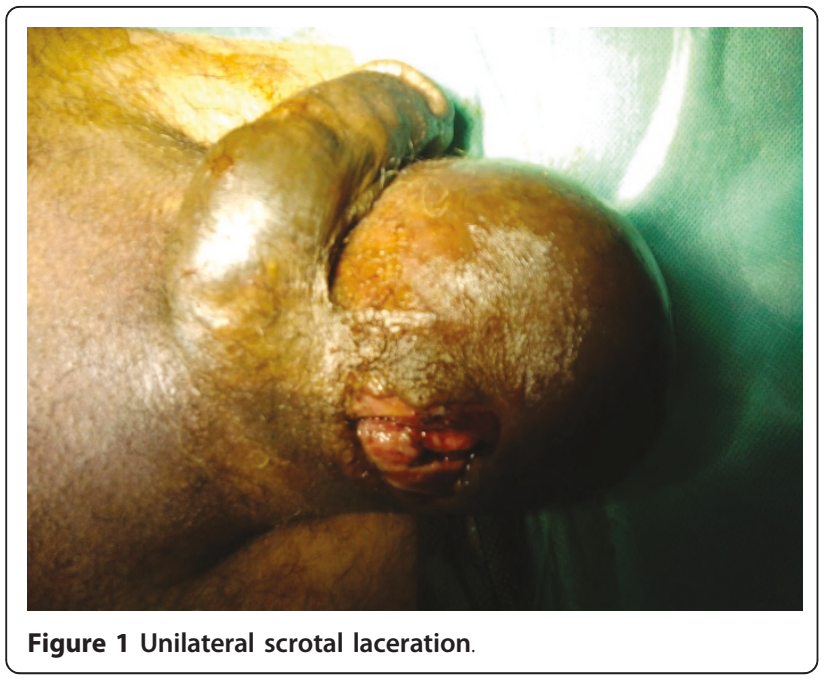

region. There was increase in scrotal volume due to the hematoma, with no active hemorrhage found (Figure 4). Our patient was interviewed by our psychiatrist, who found appropriate orientation and good contact. His speech was normal, with emotional indifference. His mood was mildly depressed, following the events that led to his admission. He reported no suicidal ideation, suicidal behavior, or desire for self-injury, and had no psychotic ideation. Computed tomography with intravenous contrast was performed to localize his spermatic cord, which was fortunately not retracted into the inguinal or retroperitoneal region. After stabilization of his psychiatric state with a benzodiazepine drug (diazepam: 30 drops a day), our patient was admitted to the operating room and haemostasis was easily achieved after ligation of both spermatic cords (Figure 5). The dartos and skin were then closed in two layers, with a good postoperative result. Our patient was discharged after his

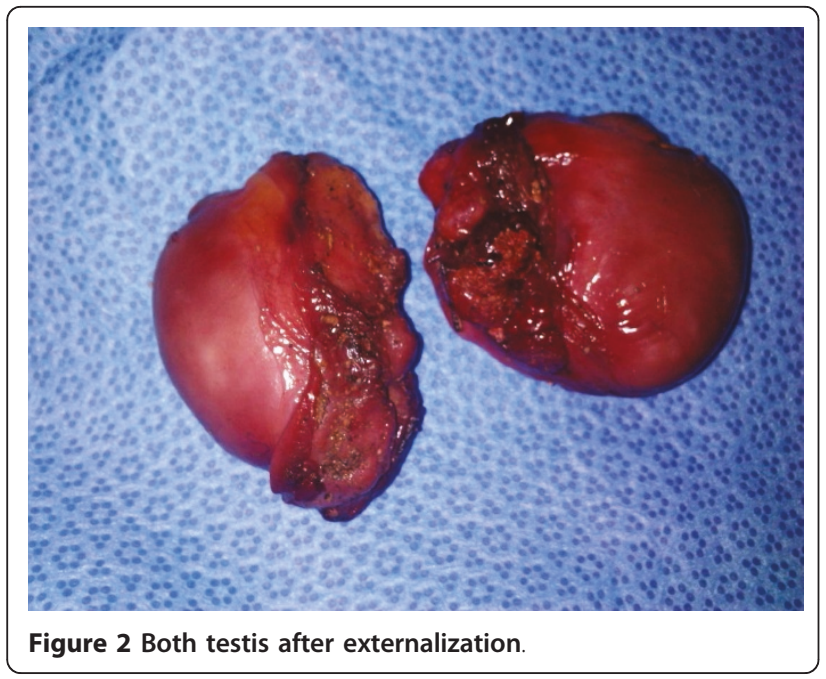

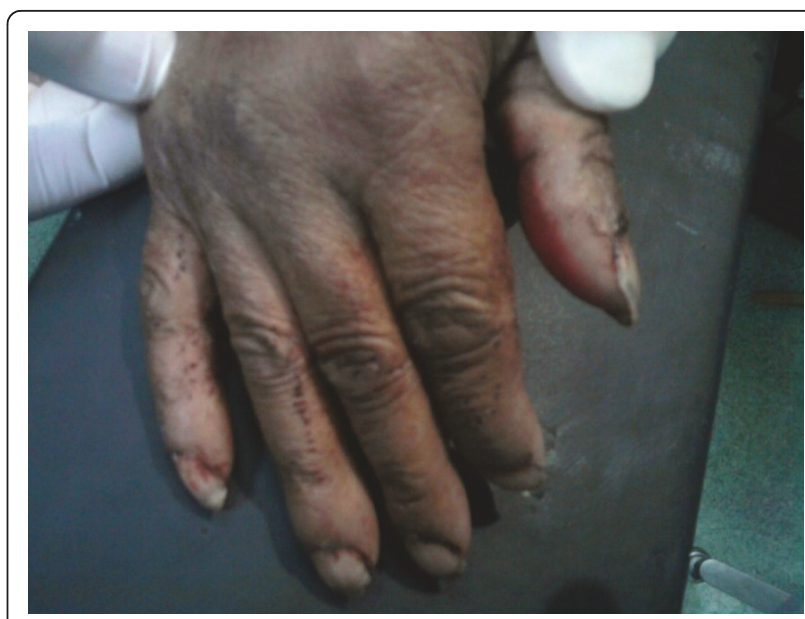

Figure 3 Long fingernails.

second day to a psychiatric department for supplement care and for substitution therapy for his cannabis use.

\section{Discussion}

Self-mutilation, a very unusual situation in routine urology, is a direct and deliberate harm to one's body without conscious intent to die. It is observed in both men and women with various psychiatric disorders [6]. Selfcastration is an uncommon phenomenon. It usually occurs in the context of a psychotic disorder, specifically schizophrenia [7], with evidence suggesting an increased prevalence of psychosis surrounding the time of self-castration $[2,8]$. Genital self-mutilation has also been documented in other patient populations, including individuals suffering from character pathology [7], substance abuse [4], gender identity issues [9], issues of religious content, guilt, sexual conflict, and with a history of depression with a severe suicide attempt, severe

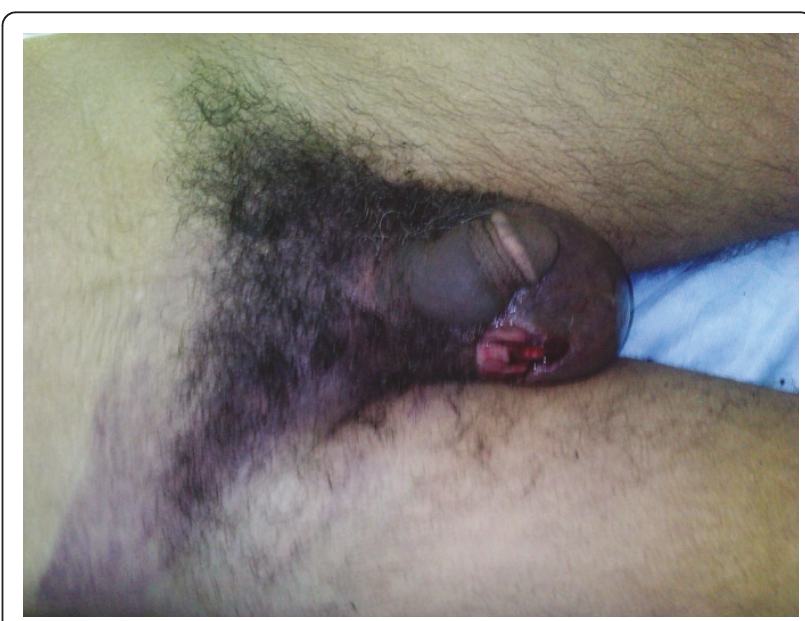

Figure 4 Ecchymosis skin extended from his scrotum to the inguinal region. 


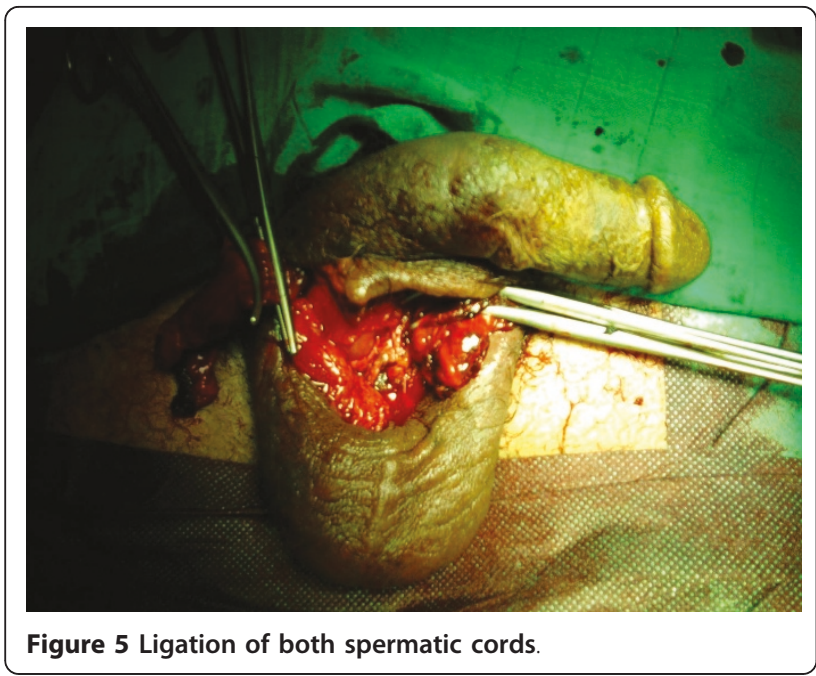

childhood deprivation, loss of a father and sexual identity disturbances specific to males [8]. Few cases have been reported within the last 20 years.

We report here the first case of a patient who self-mutilated his testes with his long fingernails under the influence of cannabis. Many theories consider self-mutilation to be a strategy to reduce distress or tension, an expression of anger or shame, or manipulative behavior. Some authors link this behavior to borderline personality disorder [10] or treat it as a means for the patient of controlling traumatic childhood experiences [11]. Our patient, however, had no history of childhood trauma or any axis II disorder. A high consumption of cannabis just before his act led us to the belief that cannabis abuse was the trigger for testicular self-mutilation. Self-mutilation may also be linked to difficulties in impulse control, as here. In any case, the clinical characteristics of self-mutilation are manifold, and its etiology is a topic for debate [12].

Cannabis, also known as "marijuana", "marihuana", "hashish" and "ganja", is a psychoactive drug, which is forbidden in many states. It is very prevalent in Africa, especially in Morocco, and in South America. There is a close relationship between dopamine and self-mutilation. High doses of dopaminergic agonists, such as amphetamine, can engender self-mutilation. We know that psychoactive substances (such as cocaine and cannabis) alter synaptic transmission by interacting with dopamine transporters, and that their dopaminergic action is one of their most important neurobiological properties. Gorea and Lombard report that the dopaminergic system may participate in mutilating behavior in rats [13].

The complex behavior associated with cannabis abuse may be one cause of self-mutilation. In animals, delta-9-tetrahydrocannabinol enhances dopaminergic neurotransmission in brain regions known to be implicated in psychosis. Studies in humans show that genetic vulnerability may add to increased risk of developing psychosis and cognitive impairments following cannabis consumption. Delta-9-tetrahydrocannabinol induces psychotic like states and memory impairments in healthy volunteers [14]. Dysfunction of the inhibitory brain circuitry in drug addiction [15] could explain why this patient lost control and mutilated himself following drug use.

Treatment for this patient population can be challenging. An integrated liaison-type psychiatric intervention can be effective in improving compliance with psychiatric treatment, surgical outcomes and reducing medical consumption [16]. The first step in the treatment of our patient was to admit to the surgical unit to achieve haemostasis. We had to first perform computed tomography with intravenous contrast to locate his spermatic cord, as our choice of incision depended on its location. If the spermatic cord is not retracted, a scrotal incision should be made, but in cases where the spermatic cord is not visible, then inguinal or retroperitoneal exploration should be attempted to gain access to the testicular vessels and provide hemostasis. Secondly, evidence has implicated serotonergic depletion and dopaminergic stimulation in self-injurious behaviors, supporting the use of paroxetine and risperidone, respectively, in this case $[17,18]$. Some authors have authorized the use of mood stabilizers such as lithium, valproic acid, or carbamazepine as alternative treatments. The role of psychotherapy can be effective for these patients in establishing a therapeutic alliance with a care provider and providing ego support.

Lastly, hormone replacement therapy based on testosterone was proposed to the patient and his family (with different pharmaceutical presentations: intramuscular, oral, patch). The risks of not treating this castration state were illustrated, with major risks being cardiovascular and osteoporotic, and other minor risks including asthenia, obesity and mood disorder.

\section{Conclusion}

Self-mutilation behavior is increasingly observed in emergency departments, but the relationship between genital injuries and substance addiction, particularly cannabis abuse, has to the best of our knowledge never been described. This case report is therefore interesting and can lead to new investigation in this area.

\section{Consent}

Written informed consent was obtained from the patient for publication of this manuscript and accompanying 
images. A copy of the written consent is available for review by the Editor-in-Chief of this journal.

\author{
Author details \\ ${ }^{1}$ Department of Urology, Hospital University Center Hassan II, 30000 Fez, \\ Morocco. ${ }^{2}$ Department of Anesthesia and Intensive Care Unit, Hospital \\ University Center Hassan II, 30000 Fez, Morocco. ${ }^{3}$ Department of Urology, \\ Academic Medical Center, PO Box 22660, 1100 DD, Amsterdam, The \\ Netherlands.
}

\section{Authors' contributions}

MA was the principal author and a major contributor in writing the manuscript. MFT analyzed and interpreted the patient data and review of the literature. AK, MJE, MHF read and corrected the manuscript. $\mathrm{AB}$ and $\mathrm{KL}$ both provided medical and surgical support for this case, and contributed to the writing of the paper. RSW contributed to the writing of the paper. All authors read and approved the final manuscript.

\section{Competing interests}

The authors declare that they have no competing interests.

Received: 12 December 2010 Accepted: 23 August 2011

Published: 23 August 2011

\section{References}

1. Romilly CS, Isaac MT: Male genital self-mutilation. Br J Hosp Med 1996, 55(7):427-431.

2. Greilsheimer H, Groves JE: Male genital self-mutilation. Arch Gen Psychiatry 1979, 36(4):441-447.

3. Money J, DePriest M: Three cases of genital self-surgery and their relationship to transsexualism. J Sex Res 1976, 12(4):283-211.

4. Israel JA, Lee K: Amphetamine usage and genital self-mutilation. Addiction 2002, 97(9):1215-1223.

5. Karila L, Ferreri M, Coscas S, Cottencin O, Benyamina A, Reynaud M: Selfmutilation induced by cocaine abuse: the pleasure of bleeding. Press Med 2007, 36(2 Pt 1):235-242.

6. Favazza A: Why patients mutilate themselves. Hosp Community Psychiatry 1989, 40(2):137-145.

7. Myers WC, Nguyen M: Autocastration as a presenting sign of incipient schizophrenia. Psychiatr Serv 2001, 52(5):685-691.

8. Nakaya M: On background factors of male genital self-mutilation. Psychopathology 1996, 29(4):242-250.

9. Murphy D, Murphy M, Grainger R: Self-castration. Ir J Med Sci 2001, 170(3):195..

10. Starr DL: Understanding those who self mutilate. J Psychosoc Nurs Ment Health Serv 2004, 42(6):32-38.

11. Cavanaugh RM: Self-mutilation as a manifestation of sexual abuse in adolescent girls. J Pediatr Adolesc Gynecol 2002, 15(2):97-100.

12. Winchel RM, Stanley M: Self-injurious behavior: a review of the behavior and biology of self-mutilation. Am J Psychiatry 1991, 148(3):306-324.

13. Gorea E, Lombard MC: The possible participation of a dopaminergic system in mutilating behavior in rats with forelimb deafferentation. Neurosci Lett 1984, 48(1):75-80.

14. Linszen D, van Amelsvoort T: Cannabis and psychosis: an update on course and biological plausible mechanisms. Curr Opin Psychiatry 2007, 20(2):116-120.

15. Goldstein RZ, Volkow ND: Drug addiction and its underlying neurobiological basis: neuroimaging evidence for the involvement of the frontal cortex. Am J Psychiatry 2002, 159(10):1642-1652.

16. van Moffaert MM: Integration of medical and psychiatric management in self-mutilation. Gen Hosp Psychiatry 1991, 13(1):59-67.

17. Goldstein M, Kuga S, Kusano N, Meller E, Dancis J, Schwarcz R: Dopamine agonist induced self-mutilative biting behavior in monkeys with unilateral ventromedial tegmental lesions of the brainstem: possible pharmacological model for Lesch-Nyhan syndrome. Brain Res 1986, 36(12):114-120.

18. Virkkunen M, Rawlings R, Tokola R, Poland RE, Guidotti A, Nemeroff C, Bissette G, Kalogeras K, Karonen SL, Linnoila M: CSF biochemistries, glucose metabolism, and diurnal activity rhythms in alcoholic, violent offenders, fire setters, and healthy volunteers. Arch Gen Psychiatry 1994, 51(1):20-27.

doi:10.1186/1752-1947-5-404

Cite this article as: Ahsaini et al:: Bilateral testicular self-castration due to cannabis abuse: a case report. Journal of Medical Case Reports 2011 5:404.

\section{Submit your next manuscript to BioMed Central and take full advantage of:}

- Convenient online submission

- Thorough peer review

- No space constraints or color figure charges

- Immediate publication on acceptance

- Inclusion in PubMed, CAS, Scopus and Google Scholar

- Research which is freely available for redistribution 